\title{
Glicerina de baixa pureza na suplementação de bovinos terminados a pasto: análise bioeconômica
}

\section{Low purity glycerin supplementation in grazing cattle: bioeconomic analysis}

\author{
Evani Souza de Oliveira Strada ${ }^{1 *}$; Robério Rodrigues Silva ${ }^{2}$; \\ Gleidson Giordano Pinto de Carvalho ${ }^{3}$; Larissa Pires Barbosa ${ }^{1}$; \\ Fabiana Lana de Araújo ${ }^{1}$; Meiby Carneiro de Paula Leite ${ }^{1}$; Laudi Cunha Leite ${ }^{1}$; \\ Cinara Conceição Peixoto ${ }^{4}$; Mateus de Melo Lisboa ${ }^{5}$
}

\begin{abstract}
Resumo
Objetivou-se avaliar a ingestão de matéria seca, digestibilidade dos componentes da dieta, desempenho, conversão alimentar, características de carcaça e aspectos econômicos da inclusão de glicerina com baixa pureza na suplementação de bovinos terminados em pastagem com Brachiaria decumbens. Utilizou-se 35 bovinos machos, não castrados, com predominância da raça Nelore, com peso corporal médio inicial de 428,0 $\pm 32,11 \mathrm{~kg}$, distribuídos em delineamento inteiramente casualizado, com cinco tratamentos e sete repetições. Os tratamentos consistiram de teores de inclusão da glicerina $(0,3,6,9$ e 12\%) na matéria seca (MS). Os animais foram pesados a cada 28 dias para avaliação do ganho de peso médio diário (GMD) e ajuste da ração. Ao final do experimento os animais foram pesados para obtenção do peso corporal médio final (PCF) e abatidos para a avaliação do rendimento de carcaça quente (RCQ) e das características de carcaça. A análise econômica foi realizada em relação ao ganho de peso em arrobas, a fim de se verificar a viabilidade do uso das rações com cinco teores de glicerina, sem considerar os demais custos fixos e operacionais. Houve efeito linear crescente $(\mathrm{P}<0,05)$ dos teores de glicerina sobre a ingestão e coeficiente de digestibilidade do extrato etéreo e GMD. Efeito linear decrescente $(\mathrm{P}<0,05)$ sobre os coeficientes de digestibilidade da fibra em detergente neutro (CDFDN), proteína bruta $(\mathrm{CDPB})$ e conversão alimentar $(\mathrm{CA})$. Não foram observados efeitos $(\mathrm{P}<0,05)$ da inclusão da glicerina sobre as características de carcaça avaliadas. A inclusão da glicerina reduziu o custo de produção de arroba de carne quando o preço desse ingrediente representou até $70 \%$ do preço do milho. A glicerina de baixa pureza pode ser incluída na dieta de bovinos não castrados em terminação a pasto com melhoria do desempenho e aumento dos benefícios econômicos.
\end{abstract}

Palavras-chave: Alimentos alternativos, glicerol, pecuária de corte, rentabilidade, suplementação

\footnotetext{
Abstract

This study aimed to evaluate the dry matter intake, digestibility of diet components, performance, feed conversion, carcass characteristics and economics aspects of inclusion with low purity glycerin

Profs., Universidade Federal do Recôncavo da Bahia, UFRB, Cruz das Almas, BA. E-mail: evanistrada@ufrb.edu.br; 1pires73@ yahoo.com.br; fabianalanadearaujo@hotmail.com; meiby@ufrb.edu.br; laudi@ufrb.edu.br

2 Prof., Universidade Estadual do Sudoeste da Bahia, UESB, Itapetinga, BA. E-mail: rrsilva.uesb@hotmail.com

3 Prof., Universidade Federal da Bahia, UFBA, Salvador, BA. E-mail: gleidsongiordano@yahoo.com.br

${ }^{4}$ Discente do Curso de Mestrado em Ciência Animal, UFRB, Cruz das Almas, BA. E-mail: cinarapeixoto@yahoo.com.br

${ }^{5}$ Discente do Curso de Mestrado em Zootecnia, UESB, Itapetinga, BA. E-mail: teteubahia@hotmail.com

* Autor para correspondência
} 
supplementation on cattle finished on pasture with Brachiaria decumbens. We used 35 male cattle bulls, predominantly Nellore, with initial body weight of $428.0 \pm 32.11 \mathrm{~kg}$, distributed in a completely randomized design with five treatments and seven replications. Treatments consisted of glycerin inclusion levels $(0,3,6,9$ and $12 \%)$ in the dry matter (DM). The animals were weighed every 28 days to assess the weight gain (ADG) and adjust the diet. At the end of the experiment the animals were weighed to obtain the average final body weight (BWF) and slaughtered to evaluate the carcass yield (HCY) and carcass traits. The economic analysis was conducted in relation to weight gain in kilos, in order to verify the feasibility of the use of diets with five levels of glycerin, without considering other fixed and operational costs. Increased linearly $(\mathrm{P}<0.05)$ levels of glycerin on the intake and digestibility of ether extract and ADG. Linear effect $(\mathrm{P}<0.05)$ on the digestibility of neutral detergent fiber (CDFDN), crude protein $(\mathrm{CDCP})$ and feed conversion $(\mathrm{FC})$. No effects were observed $(\mathrm{P}<0.05)$ the inclusion of glycerin on carcass traits evaluated. The inclusion of glycerin reduced the cost of production of meat at sign when the price of this ingredient represented up to $70 \%$ of the price of corn. Glycerin low purity can be included in the diet of cattle uncastrated finishing the pasture with improved performance and increased economic benefits.

Key words: Alternative food, beef cattle, glycerol, profitability, supplementation

\section{Introdução}

No Brasil, os rebanhos de ruminantes criados extensivamente a pasto apresentam baixa velocidade de crescimento e queda na produtividade, fatos resultantes da influência negativa da sazonalidade de produção e/ou da baixa qualidade das forrageiras, aliado ao manejo inadequado das pastagens (OLIVEIRA; FERREIRA; LEÃO, 2011).

Neste contexto, a suplementação dos animais tem se constituído numa das principais alternativas, pois segundo Moreira et al. (2004) esta tecnologia permite corrigir dietas desequilibradas, aumentar a eficiência de conversão dos pastos, melhorar o ganho de peso dos animais, encurtar os ciclos reprodutivos, de crescimento e engorda dos bovinos e aumentar a capacidade de suporte dos sistemas produtivos. Entretanto, o custo do suplemento é considerado alto, já que o milho, um dos ingredientes energéticos de maior importância para terminação de bovinos de corte, possui elevado custo (KAZAMA et al., 2008).

Para viabilizar sistemas de produção animal a pasto, com uso de suplementos, a utilização de alimentos alternativos que possam substituir parte do concentrado fornecido, para reduzir o custo de produção sem prejudicar o consumo e o desempenho dos animais, é um objetivo a ser alcançado (GUNN; SCHULTZ; VAN EMON, 2010).
A glicerina, coproduto do processo de transesterificação na formação do biodiesel, por apresentar características energéticas semelhantes ao milho está sendo amplamente pesquisada em substituição parcial a esse alimento em dietas para ruminantes (FAPRI, 2013). As pesquisas buscam avaliar, por meio do aspecto nutritivo, digestibilidade e desempenho (FARIAS et al., 2012; MACH; BACH; DEVANT, 2009); dos parâmetros ruminais (FERRARO et al., 2009; ABO EL-NOR et al., 2010; RAMOS; KERLEY, 2012) da produção e qualidade da carne (PARSONS; SHELOR; DROUILLARD, 2008; PELLEGRIN et al., 2012) e da viabilidade econômica (LAGE et al., 2010; COSTA; SILVA; PIRES, 2013) os melhores teores de substituição para cada espécie animal e categoria.

Tendo em vista a escassez de trabalhos que aborda a utilização deste coproduto na dieta de ruminantes em pastagens a avaliação bioeconômica pode contribuir para o melhor entendimento do uso deste composto para bovinos de corte.

Desse modo, objetivou-se avaliar o efeito da inclusão da glicerina de baixa pureza na suplementação de bovinos não castrados terminados em pastagem de Brachiaria decumbens por meio do consumo, digestibilidade dos componentes nutricionais, desempenho animal, características de carcaça e aspectos econômicos. 


\section{Material e Métodos}

O experimento foi conduzido no Setor de Bovino de Corte da Universidade Federal do Recôncavo da Bahia (UFRB), campus de Cruz das Almas - BA, em uma área de 35 hectares (ha) formada com Brachiaria decumbens, dividida em cinco piquetes com, aproximadamente, sete ha cada, com acesso a praça de alimentação.

O período experimental compreendeu os meses de setembro a dezembro de 2010, num total de 88 dias, sendo os primeiros 14 dias destinados à adaptação dos animais às condições experimentais e 74 dias para coletas dos dados.

Utilizou-se 35 bovinos machos não castrados, mestiços, com predominância da raça Nelore, com peso corporal inicial médio de 428,0 $\pm 32,11$ $\mathrm{kg}$, suplementados na proporção de $1,0 \%$ do peso corporal (PC), distribuídos em um delineamento inteiramente casualizado, com cinco tratamentos e sete repetições.

Os suplementos continham 0, 3, 6, 9 e 12\% de inclusão de glicerina de baixa pureza na ração total, sendo formuladas segundo o NRC (2000) para atender as exigências de mantença e ganho de peso médio diário (GMD) de 1,2 $\mathrm{kg} \mathrm{dia}^{-1}$ (Tabela 1) e fornecidas diariamente às 11 horas.

Os animais foram pesados a cada 28 dias, sempre após um jejum alimentar de 14 horas, para acompanhamento do desempenho animal e ajuste da ração.

Tabela 1. Composição percentual dos suplementos com base na matéria seca e composição química dos suplementos e pasto ofertados.

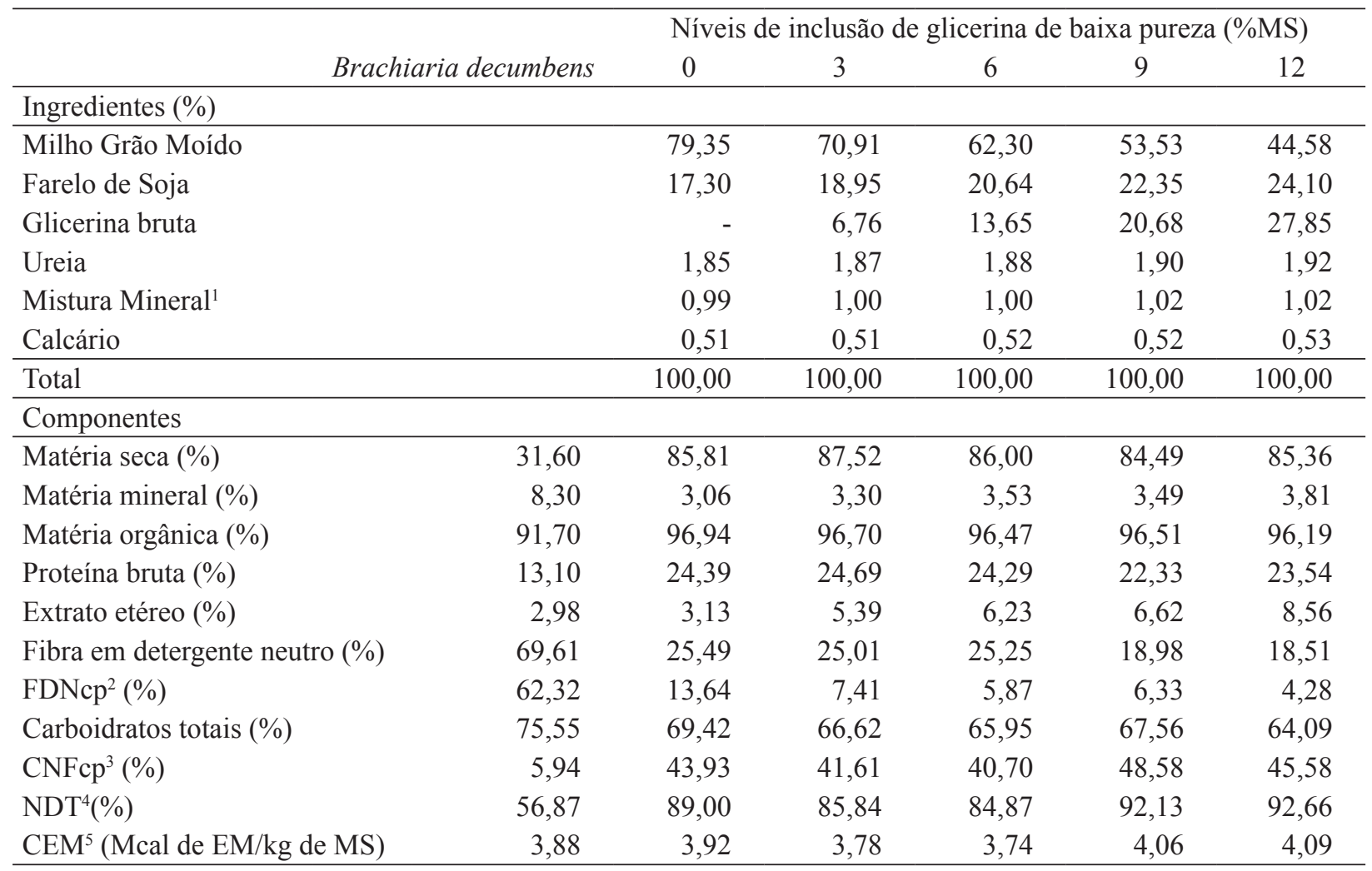

${ }^{1}$ Composição em 100g: Cloreto de sódio (NaCl) - 47,15g; Fosfato bicálcico - 50g; Sulfato de zinco - 1,5g; Sulfato de cobre- 0,75g; Sulfato de cobalto - $0,05 \mathrm{~g}$; Iodato de potássio - $0,05 \mathrm{~g}$; Sulfato de magnésio- $0,5 \mathrm{~g}$. ${ }^{2}$ Fibra em detergente neutro corrigida para cinzas e proteínas; ${ }^{3}$ Carboidratos não fibrosos corrigidos para cinzas e proteínas; ${ }^{4}$ Nutrientes digestíveis totais $;{ }^{5}$ Concentração de energia metabolizável.

Fonte: Elaboração dos autores. 
A excreção fecal foi estimada através da lignina isolada e purificada de eucalipto (LIPE ${ }^{\circledR}$ ). $\mathrm{O}$ LIPE $^{\circledR}$ foi fornecido diariamente às 9 horas em dose única de uma cápsula de $0,5 \mathrm{~g} \mathrm{~d}^{-1}$ animal (SALIBA; FERREIRA; PEREIRA, 2003), direto na boca, durante sete dias consecutivos. As fezes foram coletadas diretamente na ampola retal, uma vez ao dia, durante cinco dias, no momento da administração do indicador, e armazenadas em câmara fria a $-10^{\circ} \mathrm{C}$. Após secagem das amostras, as mesmas foram enviadas à Escola de Veterinária da Universidade Federal de Minas Gerais, para que fossem realizadas as análises do $\operatorname{LIPE}^{\circledR}$ de acordo com metodologia descrita por Saliba, Ferreira e Pereira (2003).

A ingestão de MS de suplemento (IMSS) foi estimada com a utilização do indicador externo óxido crômico, o qual foi fornecido na quantidade de $10 \mathrm{~g} \mathrm{~d}^{-1}$ por animal, misturado ao suplemento, durante doze dias, segundo procedimento descrito por Valadares Filho, Paulino e Magalhaes (2006), seguindo o mesmo manejo de coletas de fezes descrito para o LIPE. As amostras foram secas em estufa de ventilação forçada e trituradas para obtenção de amostras compostas. As amostras de fezes foram analisadas quanto aos teores de cromo conforme metodologia descrita por Kimura e Miller (1957) utilizando-se digestão nitroperclórica e espectrofotometria de absorção atômica (EAA).

O cálculo usado foi:

$$
\mathrm{IMSS}=\left(\mathrm{EF} \times \mathrm{CrO}_{2} \text { Fezes }\right) \div \mathrm{CrO}_{2} \text { Suplemento }
$$

Onde: IMMS = ingestão de MS do suplemento; $\mathrm{EF}=$ excreção fecal estimada pelo $\mathrm{LIPE}^{\circledR} ; \mathrm{CrO}_{2}$ Fezes e $\mathrm{CrO}_{2}$ Suplemento $=$ referem-se à concentração de óxido crômico nas fezes e no suplemento, respectivamente.

A ingestão de MS do volumoso (IMSV) foi estimada a partir da FDNi, um indicador interno obtido após incubação ruminal por 240 horas (CASALI et al., 2008), de 0,5 g de amostras de alimentos e fezes, utilizando sacos confeccionados com tecido não tecido (TNT) gramatura 100 (100 g. $\left.\mathrm{m}^{2}\right), 5$ x $5 \mathrm{~cm}$. O material remanescente da incubação foi submetido à extração com detergente neutro, para determinação da FDNi.

A IMSV foi calculada da seguinte forma:

\section{$\operatorname{IMSV}(\mathrm{kg} / \mathrm{dia})=[(\mathrm{EF} \times \mathrm{CIF})-\mathrm{CIS}] \div \mathrm{CIV}+$ CMSS}

Em que: $\mathrm{EF}=$ excreção fecal $(\mathrm{kg} / \mathrm{dia})$, obtida utilizando-se o LIPE $^{\circledR} ;$ CIF = concentração do FDNi nas fezes $(\mathrm{kg} / \mathrm{kg})$; CIS = consumo da FDNi a partir do volumoso e $\mathrm{CIV}=$ concentração do FDNi no volumoso $(\mathrm{kg} / \mathrm{kg})$.

A IMST ( $\mathrm{kg} / \mathrm{dia})$ foi estimada pelo somatório da IMSS e IMSV.

O coeficiente de digestibilidade do nutriente (CD) foi calculado a partir da seguinte equação:

CD $(1-(\%$ FDNi no Ingerido $\div \%$ FDNi nas fezes $) \times(\% \mathrm{NEF} \div \% \mathrm{NEI})) \times 100$

Em que: $\mathrm{NEF}=$ nutriente estudado nas fezes; $\mathrm{NEI}=$ nutriente estudado no ingerido.

As análises químicas das amostras da forragem, dos suplementos (Tabela 1) e das fezes foram realizadas no laboratório de Nutrição Animal da Universidade Estadual do Sudoeste da Bahia em Itapetinga-BA. Foram avaliados os teores de MS, massa orgânica (MO), PB, EE, segundo técnicas descritas por Silva e Queiroz (2002). Para a determinação da fibra em detergente neutro (FDN) utilizou-se a metodologia proposta por Van Soest, Robertson e Lewis (1991).

Os carboidratos totais (CHOT) estimados segundo Sniffen et al. (1992), como:

$$
\mathrm{CHOT}=100-(\% \mathrm{~PB}+\% \mathrm{EE}+\% \text { cinzas }) . \mathrm{O}
$$
conteúdo de carboidratos não-fibrosos (CNF), pela diferença entre CHOT e FDN e os teores de carboidratos não-fibrosos corrigidos para cinzas e proteína (CNFcp) foram calculados como proposto por Detmann e Valadares Filho (2010).

$$
\mathrm{CNF} c p=(100-(\% \text { FDNcp }-(\% \mathrm{~PB}-\mathrm{Pbu}+\mathrm{U})
$$
- \% EE - \% cinzas )), em que: $\mathrm{PBu}=$ proteína bruta 
da ureia; $\mathrm{U}=$ quantidade de ureia.

Os nutrientes digestíveis totais (NDT) foram calculados segundo Weiss (1999), utilizando-se a seguinte equação: $\mathrm{NDT}(\%)=\mathrm{PBD}+\mathrm{FDNcpD}+$ CNFcpD + 2,25 EED

Em que: PBD, FDNcpD, CNFcpD e EED representam, respectivamente, ingestões de $\mathrm{PB}$, FDNcp, CNFcp e EE digestíveis. Os teores de nutrientes digestíveis totais estimados (NDTest) dos alimentos e rações totais, foram calculados conforme equações descritas pelo NRC (2001).

Para a energia metabolizável, considerouse que $1,0 \mathrm{~kg}$ de NDT equivalem a 4,409 Mcal de energia digestível e para a transformação em energia metabolizável utilizou-se o valor de $82 \%$ de eficiência de utilização de energia digestível.

A glicerina utilizada foi analisada pelo método de Karl Fischer no Instituto de Tecnologia do Paraná - TECPAR, Curitiba - PR e apresentou a seguinte composição físico-química em porcentagem na matéria natural: 43,9\% de glicerol, 6,0\% de metanol, 33,6 \% de ácidos graxos totais, 9,0\% de água e 7,3\% de matéria mineral.

O GMD foi determinado pela diferença entre o peso corporal inicial (PCI) e o peso corporal final (PCF) dividido pelo total de dias para coleta dos dados.

A conversão alimentar (CA) da matéria seca (MS) foi calculada em função da ingestão de MS e do desempenho animal conforme a equação:

$\mathrm{CA}=(\mathrm{IDMS} / \mathrm{GMD})$,

Sendo: IDMS = ingestão diária de matéria seca ( $\mathrm{kg} \mathrm{MS} / \mathrm{dia})$ e GMD = ganho de peso médio diário (kg/dia).

O abate dos animais ocorreu segundo rotina do frigorifico comercial. Logo após o abate, as carcaças foram identificadas e pesadas para mensuração do peso de carcaça quente (PCQ) e rendimento de carcaça quente (RCQ). Posteriormente, as mesmas foram resfriadas por 24 horas a $2{ }^{\circ} \mathrm{C}$. Após o resfriamento, utilizou-se o lado direito da carcaça para avaliar as características quantitativas.

O comprimento de carcaça (CC) foi medido com o auxílio de uma trena, mensurando a distância do bordo anterior do osso púbis ao bordo cranial medial da primeira costela. Para o comprimento de perna (CP) utilizou-se um compasso de alumínio, medindo-se a distância compreendida entre o bordo anterior do osso do púbis e um ponto médio dos ossos da articulação do tarso. Na sequência, aferiu-se esta distância com o auxílio de uma trena. A espessura do coxão (EC) foi determinada com auxílio de um compasso de alumínio e a distância compreendida entre a face lateral e a medial da porção superior do coxão foram mensuradas com o auxílio de uma trena.

A área de olho de lombo (AOL) foi determinada após corte transversal entre a $12^{\mathrm{a}} \mathrm{e}$ $13^{\text {a }}$ costelas, expondo-se o músculo Longissimus dorsi. Posteriormente, utilizando um planímetro desenvolvido por Luchiari Filho (2000) determinouse a área em $\mathrm{cm}^{2}$. A AOL foi ajustada para $100 \mathrm{~kg}$ de peso corporal $\left(\mathrm{cm}^{2}\right)$ de acordo com equação:

AOL $100 \mathrm{~kg}$ PC $($ AOL $\div$ PCQ $) \times 100$

A espessura da gordura subcutânea (EGS) foi obtida com auxílio de um paquímetro de precisão mensurando três pontos equidistantes na região do corte entre $12^{\mathrm{a}}$ e $13^{\mathrm{a}}$ costelas, no músculo Longissimus dorsi.

A análise econômica foi realizada em relação ao ganho de arroba, a fim de se verificar a viabilidade do uso das rações com cinco níveis de glicerina de baixa pureza no suplemento, sem considerar os demais custos fixos e operacionais relativos à produção bovina, já que eles seriam semelhantes nas cinco situações.

Segundo Araújo, Sabbag e Lima (2012), custos fixos são aqueles que estão relacionados a fatores de produção que não podem ser modificados, em termos de quantidade utilizada, em curto período de tempo ou ciclo produtivo. Estes custos estão 
presentes na atividade, mesmo que a produção seja zero e o custo operacional total composto pelos seguintes itens: operações mecanizadas, operações manuais, materiais, depreciações e encargos financeiros (MATSUNAGA et al., 1976).

Os preços dos alimentos e da arroba de carne estão representados em unidade de Real ( $R \$$ ), referentes ao mês de setembro e dezembro de 2010. Os investimentos foram obtidos mediante o produto entre a quantidade dos materiais usados (ingredientes da ração) e os seus respectivos preços unitários.

Os dados foram avaliados por meio de Análises de Variância e de Regressão, utilizando-se o Sistema de Análises Estatísticas e Genéticas SAEG (UFV/SAEG, 2000). Os modelos estatísticos foram escolhidos de acordo com a significância dos coeficientes de regressão ao nível de 5\% de probabilidade.

\section{Resultados e Discussões}

As ingestões diárias de MS do suplemento (MSS), MS do volumoso (MSV), MS total (MST) e da fibra em detergente neutro (FDN), em kg dia ${ }^{-1}$ e em \% PC, assim como a ingestão de proteína bruta (PB), de carboidratos não fibrosos (CNF), de nutrientes digestíveis totais (NDT), de energia digestível (ED) e de energia metabolizável (EM) não foram influenciadas $(\mathrm{P}>0,05)$ pelos teores de glicerina de baixa pureza nas rações, mas a ingestão de extrato etéreo (EE) aumentou linearmente (Tabela 2).

Tabela 2. Ingestões médias diárias de nutrientes por bovinos suplementados em pastagem de Brachiaria decumbens com glicerina de baixa pureza.

\begin{tabular}{|c|c|c|c|c|c|c|c|c|}
\hline \multirow{2}{*}{ Itens } & \multicolumn{5}{|c|}{ Níveis de inclusão de glicerina (\%MS) } & \multirow[t]{2}{*}{ EPM } & \multicolumn{2}{|c|}{ P Valor } \\
\hline & 0 & 3 & 6 & 9 & 12 & & $\mathrm{~L}$ & $\mathrm{Q}$ \\
\hline $\operatorname{MSS}^{1}(\mathrm{~kg} / \mathrm{dia})$ & 4,16 & 4,60 & 3,92 & 4,78 & 3,83 & 0,15 & 0,975 & 0,490 \\
\hline MSS (\%PC) & 0,90 & 1,01 & 0,81 & 1,00 & 0,80 & 0,03 & 0,789 & 0,665 \\
\hline $\operatorname{MSV}^{2}(\mathrm{~kg} / \mathrm{dia})$ & 7,05 & 5,51 & 6,01 & 6,4 & 5,85 & 0,21 & 0,290 & 0,341 \\
\hline MSV (\%PC) & 1,54 & 1,20 & 1,23 & 1,34 & 1,25 & 0,05 & 0,263 & 0,236 \\
\hline $\operatorname{MST}^{3}(\mathrm{~kg} / \mathrm{dia})$ & 11,21 & 10,12 & 9,94 & 11,18 & 9,68 & 0,24 & 0,363 & 0,657 \\
\hline MST (\%PC) & 2,45 & 2,21 & 2,04 & 2,34 & 2,06 & 0,06 & 0,296 & 0,497 \\
\hline $\mathrm{FDN}^{4}(\mathrm{~kg} / \mathrm{dia})$ & 6,0 & 4,90 & 5,14 & 5,32 & 4,82 & 0,15 & 0,076 & 0,158 \\
\hline FDN $(\% \mathrm{PC})$ & 1,31 & 1,09 & 1,05 & 1,11 & 1,03 & 0,04 & 0,090 & 0,136 \\
\hline $\mathrm{PB}^{5}(\mathrm{~kg} / \mathrm{dia})$ & 1,88 & 1,90 & 1,80 & 1,92 & 1,61 & 0,04 & 0,186 & 0,186 \\
\hline $\mathrm{EE}^{6}(\mathrm{~kg} / \mathrm{dia})$ & 0,35 & 0,40 & 0,42 & 0,51 & 0,50 & 0,01 & $<.0001^{*}$ & $<.0001$ \\
\hline $\mathrm{CNF}^{7}(\mathrm{Kg} /$ dia $)$ & 2,53 & 2,58 & 2,20 & 3,07 & 2,40 & 0,08 & 0,471 & 0,682 \\
\hline $\mathrm{NDT}^{8}(\mathrm{Kg} / \mathrm{dia})$ & 6,90 & 6,30 & 5,80 & 7,13 & 5,08 & 0,24 & 0,169 & 0,337 \\
\hline $\mathrm{ED}^{9}$ (Mcal/dia) & 30,42 & 27,80 & 25,50 & 31,45 & 22,41 & 1,08 & 0,169 & 0,337 \\
\hline $\operatorname{EM}^{10}(\mathrm{Mcal} / \mathrm{dia})$ & 24,94 & 22,80 & 20,91 & 25,79 & 18,37 & 0,89 & 0,169 & 0,337 \\
\hline
\end{tabular}

EPM=Erro padrão da média; L, Q: ordem dos efeitos linear e quadrático para a inclusão da glicerina de baixa pureza na dieta; ${ }^{1}$ Matéria seca do suplemento; ${ }^{2}$ Matéria seca do volumoso; ${ }^{3}$ Matéria seca total ; ${ }^{4}$ Fibra em detergente neutro; ${ }^{5}$ Proteína bruta; ${ }^{6}$ Extrato etéreo; ${ }^{7}$ Carboidratos não fibrosos; ${ }^{8}$ Nutrientes digestíveis totais; ${ }^{9}$ Energia digestível; ${ }^{10}$ Energia metabolizável. ${ }^{*} \hat{Y}=0,4239 \mathrm{x}+$ 0,30926 $\left(\mathrm{R}^{2}=0,46\right)$.

Fonte: Elaboração dos autores. 
Uma vez que não houve alteração na ingestão de MSS e da MSV, a ingestão de MST também não foi modificada. Esses resultados podem está relacionados à ingestão de $\mathrm{FDN}$, pois segundo Mertens (1994), a FDN só afeta a ingestão de MS quando seu consumo não estiver entre 0,8 a $2 \%$ do PC. A ingestão média de FND observada neste trabalho foi de $1,1 \%$ do PC.

Gunn et al. (2008), também não observaram alteração na ingestão de MST ao avaliarem o desempenho de 37 novilhos e 13 novilhas com a inclusão de 15 e $30 \%$ de glicerina bruta na dieta. Para Neiva et al. (2012), a glicerina bruta pode ser incluída até o nível de $24 \%$ da MS sem alterar a ingestão de MST de novilhos e vacas de aptidão leiteira.

Entretanto, Pyatt, Doane e Cecava (2007), observaram redução na ingestão de MST por novilhos cruzados com inclusão de $10 \%$ de glicerina bruta e Parsons, Shelor e Drouillard (2008), com a inclusão acima de $8 \%$ na dieta de novilhas de corte. Aumentos da ingestão de MST foram relatados por Mach, Bach e Devant (2009), para os níveis de 4, 8 e 12\% e redução com inclusão de $16 \%$ de glicerina, enquanto para os níveis 0 e $2 \%$ não houve alteração.

As diferenças encontradas em relação aos resultados de ingestão de MST entre os trabalhos podem ser causadas tanto pela composição da glicerina que varia de acordo com o método de obtenção, quanto por seus efeitos intrínsecos ao glicerol no metabolismo ruminal. Substâncias como sais e metanol, que são utilizados no processo de transesterificação, podem influenciar a palatabilidade da glicerina obtida (CHUNG et al., 2007).

De acordo com os resultados da análise da glicerina de baixa pureza usada neste trabalho, a concentração PB é praticamente nula, o que levou ao aumento da proporção da fonte proteica com a adição de farelo de soja. Esse fato adicionado a não diferença entre os tratamentos com relação à ingestão de MST, podem ter promovido a não alteração da quantidade de PB ingerida.

$\mathrm{O}$ aumento linear na ingestão de EE pode ser explicado pela elevação do teor deste componente nutritivo no suplemento, uma vez que era 3,13 no suplemento com $0 \%$ de glicerina e passou a ser $8,56 \%$ no suplemento com $12 \%$ de glicerina de baixa pureza (Tabela 1). No entanto, neste estudo, o aumento de EE na dieta não prejudicou a ingestão da MST, pois a ingestão de EE ficou abaixo dos 6,0\% recomendado por Palmquist e Jenkins (1980) como ideal para que não haja comprometimento da fermentação ruminal.

A ingestão de CNF não foi alterada $(\mathrm{P}>0,05)$ com a inclusão de glicerina na dieta. Resposta distinta foi encontrada por Farias et al. (2012), que observaram decréscimo linear $(\mathrm{P}<0,05)$ da ingestão de CNF com a inclusão de glicerina bruta na dieta de novilhas o que, segundo os autores, pode ser justificado devido à substituição do milho pela glicerina, uma vez que a glicerina não tem carboidratos não fibrosos.

A ingestão de NDT, ED e EM não apresentaram alterações, possivelmente devido ao fato de não ter ocorrido aumento da ingestão de MST. A ingestão média de NDT encontrada neste estudo foi de 6,2 $\mathrm{kg} \mathrm{dia}^{-1}$, acima do preconizado por Detmann e Valadares Filho (2010), de 4,6 $\mathrm{kg} \mathrm{dia}^{-1}$ para animais criados a pasto.

O coeficiente de digestibilidade da MS (CDMS) não foi afetado pela inclusão de glicerina na dieta $(\mathrm{P}>0,05)$, mas os coeficientes de digestibilidade dos demais componentes da dieta: PB (CDPB), EE (CDEE), FDN (CDFDN) e CNF (CDCNF) foram alterados $(\mathrm{P}<0,05)$ (Tabela 3$)$. 
Tabela 3. Coeficiente de digestibilidade aparente de nutrientes por de bovinos suplementados em pastagem de Brachiaria decumbens com glicerina de baixa pureza.

\begin{tabular}{lcccccccl}
\hline \multirow{2}{*}{ Itens } & \multicolumn{4}{c}{ Níveis de inclusão de glicerina (\%MS) } & EPM & \multicolumn{2}{c}{ P Valor } \\
\cline { 2 - 8 } & 0 & 3 & 6 & 9 & 12 & & $\mathrm{~L}$ & \multicolumn{1}{c}{$\mathrm{Q}$} \\
\hline $\mathrm{CDMS}^{1}$ & 62,69 & 65,70 & 57,85 & 61,00 & 55,25 & 1,00 & 0,807 & 0,187 \\
$\mathrm{CDPB}^{2}$ & 63,84 & 67,52 & 61,69 & 63,64 & 52,54 & 1,29 & $0,008^{*}$ & 0,001 \\
$\mathrm{CDEE}^{3}$ & 76,01 & 80,05 & 79,51 & 84,47 & 80,75 & 0,12 & $0,001^{* *}$ & 0,0005 \\
$\mathrm{CDFDN}^{4}$ & 51,04 & 45,00 & 42,67 & 40,66 & 36,38 & 0,02 & $0,018^{* * *}$ & 0,063 \\
$\mathrm{CDCNF}^{5}$ & 78,06 & 76,20 & 71,96 & 71,927 & 59,92 & 0,02 & $0,0006^{* * * *}$ & 0,0005 \\
\hline
\end{tabular}

EPM= erro padrão da média; $\mathrm{L}, \mathrm{Q}=$ ordem dos efeitos linear e quadrático para a inclusão da glicerina de baixa pureza na dieta. ${ }^{1}$ Coeficiente de digestibilidade da matéria seca; ${ }^{2}$ Coeficiente de digestibilidade da proteína bruta; ${ }^{4}$ Coeficiente de digestibilidade do extrato etéreo; ${ }^{4}$ Coeficiente de digestibilidade da fibra em detergente neutro; ${ }^{5}$ Coeficiente de digestibilidade de carboidratos não fibrosos. ${ }^{*} \hat{Y}=-2,33798 x+68,76829\left(R^{2}=0,19\right) ;{ }^{* *} \hat{Y}=75,82593 x+1,55493\left(R^{2}=0,27\right) ;{ }^{* * *} \hat{Y}=-2,85227 x+52,73719\left(R^{2}=0,16\right)$; ${ }^{* * * *} \hat{Y}=-3,57895 x+83,30997\left(R^{2}=0,31\right)$.

Fonte: Elaboração dos autores.

A redução linear do CDPB, CDFDN e CDCNF pode ser atribuída a quedas no $\mathrm{pH}$ ruminal, em função do acúmulo de ácidos graxos de cadeia curta da fermentação de fontes rapidamente degradáveis (RUSSELL; WILSON, 1996). O pH ruminal pode variar de 5,5 a 7,2, com valores baixos detectados em intervalos de tempos curtos após alimentação dos animais com dietas ricas em concentrado (VALADARES FILHO; PINA, 2006), sendo que valores de $\mathrm{pH}$ abaixo de 6,0 podem inibir as bactérias fermentadoras de celulose e diminuir a eficiência da síntese de proteína microbiana (STROBEL; RUSSELL, 1986). Mach, Bach e Devant (2009), encontraram valor de $\mathrm{pH}$ de 5,68 em bovinos alimentados com $8 \%$ de glicerina bruta.

Estudos realizados por Farias et al. (2012), não demonstraram efeitos da inclusão de glicerina bruta sobre os coeficientes de digestibilidade da MS, PB, e FDN. Hess, Lake e Gunter (2008), relataram que a glicerina bruta pode ser adicionada até 15\% de MS sem afetar a digestibilidade da MST e da FDN. Porém, Eiras et al. (2014) e Wang et al. (2009), notaram que a digestibilidade total da MS, FDN e PB foram aumentadas linearmente com o aumento da glicerina na dieta.
Verificou-se efeito linear crescente do CDEE com a inclusão de glicerina, resultado condizente com o de Farias et al. (2012), em novilhas terminadas em confinamento. Segundo esses autores a diferença no CDEE pode ocorrer devido à composição química da glicerina ou da fonte de matéria prima ou do processo de produção do biodiesel que deu origem a glicerina utilizada.

As rações experimentais promoveram efeito linear $(\mathrm{P}<0,05)$ crescente no ganho de peso médio diário (GMD) e decrescente na conversão alimentar, mas não influenciaram $(\mathrm{P}>0,05)$ no peso corporal inicial $(\mathrm{PCI})$ e nem no peso corporal final (PCF) (Tabela 4).

Embora, não tenham sido observadas diferenças entre os tratamentos para a ingestão de MST, em função dos teores de glicerina, os animais que ingeriram maior quantidade de glicerina de baixa pureza apresentaram melhor GMD. O GMD aumentou de $1,1 \mathrm{~kg} \mathrm{dia}{ }^{-1}$ na dieta controle, para $1,37 \mathrm{~kg} \mathrm{dia}^{-1}$ na dieta com teor de $12 \%$ de inclusão de glicerina, o que representa um acréscimo de aproximadamente $25 \%$ no GMD. Esta resposta pode está relacionada à maior ingestão e digestibilidade de EE observados nos animais que foram suplementados com o maior nível de glicerina. 
Tabela 4. Desempenho e características de carcaça de bovinos suplementados em pastagem de Brachiaria decumbens com glicerina de baixa pureza.

\begin{tabular}{lrrrrrrrc}
\hline \multirow{2}{*}{ Itens } & \multicolumn{4}{c}{ Níveis de inclusão de glicerina (\%MS) } & \multicolumn{1}{c}{ EPM } & \multicolumn{2}{c}{ P Valor } \\
\cline { 2 - 8 } & \multicolumn{1}{c}{0} & \multicolumn{1}{c}{3} & \multicolumn{1}{c}{6} & \multicolumn{1}{c}{12} & & $\mathrm{~L}$ & $\mathrm{Q}$ \\
\hline $\mathrm{PCI}^{1}(\mathrm{~kg})$ & 425,71 & 424,28 & 440,00 & 425,14 & 424,42 & 5,42 & 0,964 & 0,543 \\
$\mathrm{PCF}^{2}(\mathrm{~kg})$ & 508,57 & 494,71 & 529,71 & 531,57 & 526,28 & 7,72 & 0,199 & 0,808 \\
$\mathrm{GMD}^{3}(\mathrm{~kg})$ & 1,11 & 0,95 & 1,21 & 1,43 & 1,37 & 0,49 & $0,002^{*}$ & 0,627 \\
$\mathrm{CA}^{4}(\mathrm{~kg} / \mathrm{kg})$ & 10,14 & 10,25 & 8,43 & 7,82 & 7,26 & 0,80 & $0,019^{* *}$ & 0,067 \\
$\mathrm{PCQ}^{5}(\mathrm{~kg})$ & 281,28 & 277,50 & 293,28 & 289,00 & 286,64 & 4,41 & 0,499 & 0,657 \\
$\mathrm{RCQ}^{6}(\mathrm{~kg})$ & 55,20 & 55,75 & 55,44 & 54,31 & 54,52 & 0,20 & 0,054 & 0,374 \\
$\mathrm{CC}^{7}(\mathrm{~cm})$ & 144,0 & 142,28 & 144,71 & 150,85 & 145,14 & 1,71 & 0,403 & 0,779 \\
$\mathrm{CP}^{8}(\mathrm{~cm})$ & 76,64 & 76,57 & 77,71 & 76,85 & 77,14 & 0,46 & 0,710 & 0,754 \\
$\mathrm{EC}^{9}(\mathrm{~cm})$ & 23,5 & 27,50 & 27,64 & 27,65 & 26,07 & 0,74 & 0,321 & 0,079 \\
$\mathrm{EGS}^{10}(\mathrm{~cm})$ & 2,85 & 2,35 & 3,14 & 4,07 & 3,42 & 0,22 & 0,073 & 0,938 \\
$\mathrm{AOL}^{11}\left(\mathrm{~cm}^{2}\right)$ & 76,71 & 74,57 & 83,71 & 77,14 & 68,00 & 1,91 & 0,255 & 0,06 \\
$\mathrm{AOLC}^{12}\left(\mathrm{~cm}^{2}\right)$ & 27,29 & 26,87 & 28,55 & 26,83 & 23,82 & 0,91 & 0,088 & 0,076 \\
\hline
\end{tabular}

EPM= erro padrão da média; L, Q: ordem dos efeitos linear e quadrático para a inclusão da glicerina de baixa pureza na dieta; ${ }^{1} \mathrm{Peso}$ corporal inicial; ${ }^{2}$ Peso corporal final; ${ }^{3} \mathrm{Ganho}$ de peso médio diário; ${ }^{4}$ Conversão alimentar; ${ }^{5}$ Peso da carcaça quente; ${ }^{6}$ Rendimento da carcaça quente; ${ }^{7}$ Comprimento de carcaça; ${ }^{8}$ Comprimento de perna; ${ }^{9}$ Espessura do coxão; ${ }^{10}$ Espessura de gordura subcutânea $;{ }^{11}$ Area de olho do lombo; ${ }^{12}$ Area de olho do lombo ajustada para $100 \mathrm{~kg}$ de $\mathrm{PC} .{ }^{*} \hat{\mathrm{Y}}=1,01969 \mathrm{x}+0,03333\left(\mathrm{R}^{2}=0,65\right) ;{ }^{* *} \hat{\mathrm{Y}}=-0,81809 \mathrm{x}+$ $11,22622\left(\mathrm{R}^{2}=0,16\right)$.

Fonte: Elaboração dos autores.

Neiva et al. (2012), ao avaliar a inclusão de 0, 6, 12 e $24 \%$ de glicerina bruta na terminação em confinamento de novilhos castrados de aptidão leiteira, observaram também efeito linear dos teores de inclusão de glicerina bruta sobre o GMD cujo valor para o teor de inclusão de $12 \%$ foi de $1,56 \mathrm{~kg}$ dia $^{-1}$. Entretanto, Eiras et al. (2014), não observaram efeito da inclusão de $0,6,12$ e $18 \%$ de glicerina de média pureza sobre o desempenho de touros da raça Purunã cuja média do GMD encontrada foi de 1,15 $\mathrm{kg} \operatorname{dia}^{-1}$.

Redução nos GMD de 1,64; 1,58 e 1,55 kg dia${ }^{1}$ para $0 ; 7,5$ e $15 \%$ de inclusão de glicerina bruta na dieta, respectivamente foram observados por Elam et al. (2008). Farias et al. (2012), também notaram que a adição de glicerina bruta na ração proporcionou redução linear no PVF e no GMD das novilhas suplementadas em pastagem com Brachiaria brizantha cv. Marandu.

A composição da glicerina é bastante variável, devido aos muitos métodos e ingredientes utilizados na produção do biodiesel (GOTT; EASTRIDGE, 2010) e essa variação justifica os diferentes resultados na literatura sobre a utilização desta na alimentação animal.

A diminuição da CA com a inclusão da glicerina está relacionada, provavelmente, ao aumento do GMD, pois os animais que consumiram o suplemento com $12 \%$ de glicerina apresentaram maior GMD que os animais do tratamento com 3, 6 e 9\%, porém com a ingestão de MST 7\% inferior à média da ingestão de MST destes.

Elam et al. (2008), não notaram diferença na CA de bovinos alimentados em confinamento com adição de $0 ; 7,5$ e $15 \%$ de glicerina.

As médias do PCQ e do RCQ foram de $285,5 \mathrm{~kg}$ e de $55 \%$, respectivamente valores próximos aos de $258,0 \mathrm{~kg}$ e 54,7\% obtidos por Eiras et al. (2014), em bovinos não castrados terminados em confinamento com suplemento contendo diferentes níveis glicerina de média pureza e de $300,2 \mathrm{~kg}$ e $54,42 \%$ 
obtidos por Pinto, Abrahão e Marques (2010), em tourinhos mestiços terminados em confinamento. O peso de carcaça é uma característica importante, pois o frigorifico remunera o produtor pelo peso de carcaça dos animais, reduzindo o valor pago quando a carcaça não atinge o peso mínimo de $230 \mathrm{~kg}$ (ABRAHÃO et al., 2005) ou de $225 \mathrm{~kg}$ (COSTA et al., 2002; ROTTA et al., 2009). Para o RCQ o valor adequado é 54\% (JORGE; FONTES; CERVIERI, 2003).

Com relação às características da carcaça não houve alterações atribuíveis ao tratamento dietético (Tabela 4). Esses resultados corroboram os de Mach, Bach e Devant (2009), quando avaliaram quatro níveis de glicerina $(0,4,8,12 \%)$ na dieta de touros holandeses.

O peso e o porte dos animais, independente do sexo, determinam as características de carcaça (MARQUES et al., 2006). Neste estudo, os animais apresentaram o peso corporal médio ao abate (PCA) de 518,17 kg e comprimento de carcaça (CC), comprimento de perna (CP) e a espessura do coxão (EC) de $145,4 \mathrm{~cm}, 76,78 \mathrm{~cm}$ e $26,5 \mathrm{~cm}$, respectivamente valores superiores aos encontrados $(113,8 \mathrm{~cm}, 68,2 \mathrm{~cm}$ e $21 \mathrm{~cm})$ por Marques et al. (2006), em novilhas terminadas em confinamento com PCA de 316,8 Kg. Eiras et al. (2014), em bovinos da raça Purunã alimentados com glicerina de média pureza com PCA de $472 \mathrm{~kg}$, obtiveram $123,0 \mathrm{~cm}$ para $\mathrm{CC}, 65,2 \mathrm{~cm}$ para $\mathrm{CP}$ e $26,8 \mathrm{~cm}$ para EC.

A espessura da gordura subcutânea (EGS) não foi alterada com a inclusão da glicerina, resposta não esperada, uma vez que a provável diminuição da razão acetato/propionato com a suplementação com glicerina poderia comprometer a quantidade de acetato, o qual fornece 70 a $80 \%$ das unidades de acetil para a lipogênese no tecido subcutâneo (SMITH; CROUSE, 1984). Entretanto, a dieta proporcionou elevação na ingestão de ácidos graxos o que poderia ter promovido aumento na EGS.

Conforme Felício (1993), a EGS é um indicador de qualidade da carcaça, pois indica se a dieta é de alta ou baixa energia e por modificar diretamente a velocidade de resfriamento da carcaça, comportando-se como isolante térmico. Assim, o teor baixo de gordura subcutânea (GS) pode causar alterações na qualidade da carne devido ao encurtamento dos sarcômeros durante a estocagem, em razão do frio. Por outro lado, altos teores de GS, além de indesejáveis, diminuem o rendimento da porção comestível e necessitam ser aparados para comercialização, implicando desperdícios (KAZAMA et al., 2008). Para Abrahão et al. (2008), quanto maior a EGS, maior o acabamento de carcaça, maior a percentagem de gordura intramuscular.

O valor médio de EGS foi de 3,17 mm, acima do limite mínimo de 3,00 mm exigido pela indústria (LUCHIARI FILHO, 2000) e entre os 3 a $5 \mathrm{~mm}$ exigidos para obtenção de carcaças com padrão adequado e evitar perdas por desidratação, além de escurecimento da carne durante o resfriamento (MULLER, 1987). Eiras et al. (2014) encontrou 4,5 $\mathrm{mm}$ como valor médio de EGS em touros da raça Purunã alimentados com glicerina de média pureza. Entretanto, Shelor e Drouillard (2009), notaram redução linear da EGS em bovinos alimentados com quantidades crescentes de glicerina bruta.

Os animais apresentaram valor médio de AOL de $61,9 \mathrm{~cm}^{2}$ e de AOLC de 26,7 $\mathrm{cm}^{2}$. Quando comparados com os resultados de Eiras et al. (2014), cuja a AOL foi de $66,5 \mathrm{~cm}^{2}$ e a AOLC de $26,9 \mathrm{~cm}^{2}$ observa-se que a AOL foi menor, contudo a AOLC foi semelhante. De acordo a Luchiari Filho (2000), a recomendação mínima para a AOLC é de $29 \mathrm{~cm}^{2}$.

$\mathrm{O}$ custo do ganho da arroba foi menor (R\$ $61,76)$ para o tratamento em que os animais receberam suplemento com $12 \%$ de inclusão de glicerina de baixa pureza na MS e o maior custo (R\$ $95,90)$ atribuído ao tratamento em que os animais receberam inclusão de 3\% (Tabela 5). A margem de lucro em relação ao preço recebido pela arroba de carne, também foi maior em animais alimentados com $12 \%$ de glicerina de baixa pureza na dieta. 
Tabela 5. Análise econômica das dietas experimentais em relação ao ganho em arrobas de bovinos suplementados em pastagem de Brachiaria decumbens com glicerina de baixa pureza ${ }^{1}$.

\begin{tabular}{lrrrrr}
\hline \multirow{2}{*}{\multicolumn{1}{c}{ Variáveis }} & \multicolumn{5}{c}{ Nível de inclusão de glicerina (\%MS) } \\
\cline { 2 - 6 } & \multicolumn{1}{c}{0} & \multicolumn{1}{c}{3} & \multicolumn{1}{c}{6} & \multicolumn{1}{c}{12} \\
\hline Custo do suplemento (R\$/ kg de MS) & 0,68 & 0,66 & 0,65 & 0,62 & 0,62 \\
Consumo de suplemento (kg/dia) & 4,160 & 4,610 & 3,930 & 4,780 & 4,570 \\
Custo do suplemento (R / cabeça por dia) & 2,83 & 3,04 & 2,55 & 2,96 & 2,83 \\
GMD (kg /cabeça por dia) & 1,120 & 0,952 & 1,212 & 1,438 & 1,376 \\
Preço da arroba (em R\$) & 99,00 & 99,00 & 99,00 & 99,00 & 99,00 \\
Dias para ganho de 1 arroba & 26,8 & 31,5 & 24,7 & 20,9 & 21,8 \\
Custo do suplemento (R\$ /arroba) & 75,79 & 95,90 & 63,21 & 61,82 & 61,76 \\
Margem de lucro do suplemento (\%) ${ }^{2}$ & 23,44 & 3,13 & 36,15 & 37,56 & 37,62 \\
\hline
\end{tabular}

${ }^{1}$ Os preços dos ingredientes referem-se a valores com frete incluso: milho, R $\$ 0,56 / \mathrm{kg}$; farelo de soja, R \$1,07/ kg; glicerina de baixa pureza, $\mathrm{R} \$ 0,20 / \mathrm{kg}$; suplemento mineral, $\mathrm{R} \$ 1,2 / \mathrm{kg}$; ureia, $\mathrm{R} \$ 1,20 / \mathrm{kg}$; calcário, $\mathrm{R} \$ 1,50 / \mathrm{kg} ;{ }^{2}$ Margem de lucro = (preço da arroba $(\mathrm{R} \$ / \mathrm{kg})$ - custo da dieta $(\mathrm{R} \$ /$ arroba)/preço da arroba. Considerou-se o preço recebido de $\mathrm{R} \$ 99,0$ pela arroba.

Fonte: Elaboração dos autores.

Esses resultados podem ser em decorrência da CA dos animais, que foi melhor para o teor de $12 \%$ inclusão de glicerina e pior para o teor de $3 \%$. Segundo Lage et al. (2010), o balanço ótimo entre a CA e os custos dos ingredientes da dieta definem o teor ótimo de glicerina de baixa pureza na ração, que nesse estudo foi o de $12 \%$.

Com relação aos resultados da análise de sensibilidade do custo do ganho da arroba das diferentes rações, com diferentes preços da glicerina de baixa pureza ( $\%$ do preço do milho grão), observa-se que a ração quando a glicerina de baixa pureza representar entre 35 a $40 \%$ do preço do milho (no período avaliado, o preço da glicerina de baixa pureza representou $35,7 \%$ do preço do milho) o teor ótimo é o de $12 \%$ (Tabela 6 ) o que foi comprovado com os resultados da margem de lucro. Esse teor se mantém como ideal até a glicerina de baixa pureza representar $70 \%$ do preço do milho.

Porém, quando o preço da glicerina de baixa pureza for referente a valores entre $70 \%$ e $160 \%$ do preço do milho, recomenda-se a inclusão de $6 \%$ de glicerina no concentrado. A partir do percentual de $160 \%$, não se indica a inclusão de glicerina de baixa pureza na ração para bovinos em fase de terminação. A inclusão de $3 \%$ de glicerina de baixa pureza não é indicada em nenhuma situação, pois devido, provavelmente, ao pior valor de CA observado para esse tratamento o custo da dieta ficou superior àquela sem glicerina.

De acordo com Lage et al. (2010), a inclusão de até $6 \%$ de glicerina bruta otimiza a CA dos animais e reduz o custo do ganho de carcaça quando o preço do coproduto representa até $70 \%$ do preço do milho, ao avaliar a inclusão de 0, 3, 6, 9 e 12\% de glicerina bruta na ração de cordeiros machos não castrados da raça Santa Inês. Pellegrin et al. (2012), testaram o efeito de teores de glicerina bruta na ração para cordeiros em substituição ao milho e constataram redução de $19,5 \%$ no custo do suplemento entre os teores 0 e $30 \%$. 
Tabela 6. Análise de sensibilidade da variação do preço da glicerina bruta (\% do preço do milho) sobre o custo do ganho de carcaça ( $\mathrm{R} \$ \mathrm{~kg}$ / de ganho em arroba) de bovinos suplementados em pastagem de Brachiaria decumbens com glicerina de baixa pureza.

\begin{tabular}{lccccc}
\hline $\begin{array}{l}\text { Preço da glicerina } \\
\text { (\% do preço do milho) }\end{array}$ & \multicolumn{5}{c}{ Nível de inclusão de glicerina (\%MS) } \\
\cline { 2 - 5 } & 0 & 3 & 6 & 9 & 12 \\
\hline 0 & 75,37 & 94,04 & 63,18 & 60,75 & 56,95 \\
10 & 75,37 & 94,04 & 63,93 & 61,99 & 58,48 \\
20 & 75,37 & 94,04 & 64,67 & 63,24 & 60,00 \\
30 & 75,37 & 95,69 & 65,42 & 64,48 & 61,53 \\
40 & 75,37 & 95,69 & 66,17 & 65,73 & 63,06 \\
50 & 75,37 & 96,79 & 66,92 & 66,97 & 64,59 \\
60 & 75,37 & 96,79 & 67,67 & 68,21 & 66,12 \\
70 & 75,37 & 96,79 & 67,67 & 69,46 & 67,65 \\
80 & 75,37 & 98,43 & 69,17 & 70,70 & 69,18 \\
90 & 75,37 & 98,43 & 69,91 & 71,95 & 70,71 \\
100 & 75,37 & 98,43 & 70,66 & 73,19 & 72,24 \\
110 & 75,79 & 100,08 & 71,41 & 74,44 & 73,77 \\
120 & 75,79 & 100,63 & 72,16 & 75,68 & 75,29 \\
130 & 75,79 & 101,18 & 72,91 & 76,93 & 76,82 \\
140 & 75,79 & 101,73 & 73,66 & 78,17 & 78,35 \\
150 & 75,79 & 102,28 & 74,41 & 79,41 & 79,88 \\
160 & 75,79 & 102,83 & 75,15 & 80,66 & 81,41 \\
170 & 75,79 & 103,38 & 75,90 & 81,90 & 82,94 \\
\hline
\end{tabular}

Fonte: Elaboração dos autores.

Utilizando os mesmos teores de glicerina de baixa pureza usados nesse estudo, na dieta para vacas lactantes alimentadas com cana-de-açúcar Costa, Silva e Pires (2013), concluíram que o teor de $12 \%$ de glicerina bruta é o mais eficiente tanto no aspecto de produtividade quanto no aspecto de lucratividade.

\section{Conclusões}

A inclusão de glicerina de baixa pureza em até $12 \%$ na matéria seca total na dieta de bovinos de corte não castrados terminados a pasto, afeta a ingestão de extrato etéreo e a digestibilidade dos componentes nutricionais da dieta, mas não altera as características de carcaça, além de melhorar a conversão alimentar. A glicerina, como uma alternativa ao milho, mostra-se bastante promissora, pois permite desempenho animal superior aos animais alimentados com milho como principal fonte energética. Além disso, reduz o custo de produção de arroba de carne, quando o preço desse coproduto representa até $70 \%$ do preço do milho.

\section{Agradecimentos}

A UFRB/ Campus de Cruz das Almas, BA, a UESB/Campus de Itapetinga, BA e a FAPESB.

\section{Referências}

ABO EL-NOR, S.; ABUGHAZALEH, A. A.; POTU, R. B.; HASTINGS, D.; KHATTAB, M. S. A. Effects of differing levels of glycerol on rumen fermentation and bacteria. Animal feed Science and Tecnology, Amsterdam, v. 162, n.3, p. 99-105, 2010. 
ABRAHÃO, J. J. S.; PRADO, I. N.; PEROTTO, D.; MOLETTA, J. L. Características de carcaças e da carne de tourinhos submetidos a dietas com diferentes níveis de substituição do milho por resíduo úmido da extração da fécula de mandioca. Revista Brasileira de Zootecnia, Viçosa, MG, v. 34, n. 5, p. 1640-1650, 2005.

ARAÚJO, H. S.; SABBAG, O. J.; LIMA, B. T. M. Aspectos econômicos da produção de bovinos de corte. Pesquisa Agropecuária Tropical, Goiânia, v. 42, n. 1, p. 82-89, 2012.

CASALI, A. O.; DETMANN, E.; VALADARES FILHO, S. C.; PEREIRA, J. C.; HENRIQUES, L.T.; FREITAS, S. G.; PAULINO, M. F. Influência do tempo de incubação e do tamanho de partículas sobre os teores de compostos indigestíveis em alimentos e fezes bovinas obtidos por procedimentos in situ. Revista Brasileira de Zootecnia, Viçosa, MG, v. 37, n. 2, p. 335-342, 2008.

CHUNG, Y. H.; RICO, D. E.; MARTINEZ, C. M.; CASSIDY,T. W.; NOIROT,V.; AMES, A.; VARGE, G. A. Effects of feeding dry glycerin to early postpartum Holstein dairy cows on lactational performance and metabolic profiles. Journal of Dairy Science, Madison, v. 90, n. 12, p. 5682-5691, 2007.

COSTA, E. C.; RESTLE, J.; BRONDANI, I.; PEROTTONI, J.; FATUR, C.; MENEZES, L. F. G. Composição física da carcaça, qualidade da carne e conteúdo de colesterol no músculo Longissimus dorsi de novilhos Red Angus superprecoces, terminados em confinamento e abatidos com diferentes pesos. Revista Brasileira de Zootecnia, Viçosa, MG, v. 31, n. 1, p. 417428, 2002.

COSTA, L. T.; SILVA, F. F.; PIRES, A. J. V. Análise bioeconômica de níveis de glicerina bruta em dietas de vacas lactantes alimentadas com cana-de-açúcar. Semina: Ciências Agrárias, Londrina, v. 34, n. 2, p. 833844, 2013.

DETMANN, E.; VALADARES FILHO, S. C. Sobre a estimação de carboidratos não fibrosos em alimentos e dietas. Arquivo Brasileiro de Medicina Veterinária e Zootecnia, Belo Horizonte, v. 62, n. 4, p. 980-984, 2010.

EIRAS, C. E.; MARQUES, J. D. A.; PRADO, R. M.;VALERO, M. V.; BONAFÉ, E. G.; ZAWADZKI, F.;PEROTTO, D.; PRADO, I. N. Glycerine levels in the diets of crossbred bulls finished in feedlot: carcass characteristics and meat quality. Meat Science, Sydney, v. 96, n. 2, Part A, p. 930-936, 2014.

ELAM, N. A.; ENG, K. S.; BECHTEL, B.; HARRIS, J. M.; CROCKER, R. Glycerol from Biodiesel Production: Considerations for feedlot diets. In: SOUTHWEST NUTRITION CONFERENCE. 21., 2008, Tempe AZ.
Proceedings... Tempe: University of Arizona, 2008. p. $1-13$.

FARIAS, M. S.; PRADO, I. N.; VALERO, M. V.; ZAWADZKI, F.; SILVA, R. R.; EIRAS, C. E. Níveis de glicerina para novilhas suplementadas em pastagens: desempenho, ingestão, eficiência alimentar e digestibilidade. Ciência Rural, Santa Maria, v. 42, n. 7, p. 1177-1187, 2012.

FERRARO, S. M.; MENDOZA, G. D.; MIRANDA, L. A., GUTIÉRREZ, C. G. In vitro gas production and ruminal fermentation of glycerol, propylene glycol and molasses. Animal feed Science and Technology, Amsterdam, v. 154, n. 1-2, p. 112-118, 2009.

FOOD AND AGRICULTURAL POLICY RESEARCH INSTITUTE - FAPRI. FAPRI World Agricultural Outlook Database. Washington DC: FAPRI, 2013. Available at: $<$ http://www.fapri.iastate.edu/tools/outlook. aspx>. Accessed at: 20 feb. 2013.

FELÍCIO, P. E. Fatores ante e post-mortem que afetam a qualidade da carne vermelha. In: REUNIÃO ANUAL DA SOCIEDADE BRASILEIRA DE ZOOTECNIA, 30., 1993, Rio de Janeiro. Anais... Rio de Janeiro: Sociedade Brasileira de Zootecnia, 1993. p. 43-52.

GOTT, P.; EASTRIDGE, M. L. Variation in the chemical composition of crude glycerin. In: ANNUAL TRI-STATE DAIRY NUTRITION CONFERENCE, 19., 2010, Fort Wayne. Procedings... Fort Wayne: Indiana, 2010. p. 1-7.

GUNN, P. J.; LEMENAGER, R. P.; CLAEYS, M. C.; LAKE, S. L. Effects of distiller's dried grains with soluble and crude glycerin on performance and carcass characteristics in early weaned beef calves. Proceedings of the American Society of Animal Science, Champaign, v. 59, n. 27, p. 290-294, 2008.

GUNN, P. J.; SCHULTZ, A. F.; VAN EMON, K. L. Effects of elevated crude glycerin concentrations on feedlot performance, carcass characteristics, and serum metabolite and hormone concentrations in finishing ewe and wether lambs. The Professional Animal Scientist, Champaign, v. 22, n.26, p. 298-306, 2010.

HESS, B. W.; LAKE, S. L.; GUNTER, S. A. Using glycerin as a supplement for forage-fed ruminants. Jornal Animal Science, Champaign, v. 86, p. 392-393, 2008. Supplement 2.

JORGE, A. M.; FONTES, R. C.; CERVIERI, R. Crescimento relativo e composição do ganho de tecidos da carcaça de zebuínos de quatro raças. Revista Brasileira de Zootecnia, Viçosa, MG, v. 32, n.4, p. 986-991, 2003.

KAZAMA, R.; ZEOULA, L. M.; PRADO, I. N.; SILVA, D. C.; DUCATTI, T.; MATSUSHITA, M. Características 
quantitativas e qualitativas da carcaça de novilhas alimentadas com diferentes fontes energéticas em dietas à base de cascas de algodão e de soja. Revista Brasileira de Zootecnia, Viçosa, MG, v. 37, n. 2, p. 350-357, 2008.

KIMURA, F. T.; MILLER, V. L. Chromic oxide measurement, improved determination of chromic oxide in cow feed and feces. Journal of Agriculture and Food Chemistry, Washington, v. 5, n. 3, p. 216, 1957.

LAGE, J. F.; PAULINO, P. V. R.; PEREIRA, L. G. R.; VALADARES FILHO, S. C.; OLIVEIRA, A. S. de; DETMANN, E.; SOUZA, N. K. P.; LIMA, J. C. M. Glicerina bruta na dieta de cordeiros terminados em confinamento. Pesquisa Agropecuária Brasileira, v. 45, n. 9, p. 1012-1020, 2010.

LUCHIARI FILHO, A. Pecuária da carne bovina. São Paulo: A. Luchiari Filho, 2000. 134 p.

MACH, N.; BACH, A.; DEVANT, M. Effects of crude glycerin supplementation on performance and meat quality of Holstein bulls fed high-concentrate diets. Journal Animal Science, Champaign, v. 87, n. 2, p. 632638, 2009.

MARQUES, J. A.; PRADO, I. N.; MOLETTA, J. L.; PRADO, I. M.; PRADO, J. M.; MACEDO, L. M. A.; SOUZA, N. E.; MATSUSHITA, M. Características físico-químicas da carcaça e da carne de novilhas submetidas ao anestro cirúrgico ou mecânico terminadas em confinamento. Revista Brasileira de Zootecnia, Viçosa, MG, v. 35, n. 4, p. 1514-1522, 2006.

MATSUNAGA, M.; BEMELMANS, P. F.; TOLEDO, P. E. N.; DULLEY, R. D.; OKAWA, H.; PEROSO, I. A. Metodologia de custo utilizada pelo IEA. Agricultura em São Paulo, São Paulo, v. 23, n. 1, p. 123-39, 1976.

MERTENS, D. R. Regulation of forage intake. In: FAHEY, G. C.; COLLINS JÚNIOR, M.; MERTENS, D. R.; MOSER, L. E. Forage quality, evaluation and utilization. (Ed.). Madison, WI: American Society of Agronomy, Crop Science Society of America, and Soil Science Society of America, 1994. p. 450- 493.

MOREIRA, F. B.; PRADO, I. N.; CECATO, U.; WADA, F. Y.; MIZUBUTI, I. Y. Forage evaluation, chemical composition, and in vitro digestibility of continuously grazed star grass. Animal Feed Science and Technology, cidade, v. 113, n. 4, p. 239-249, 2004.

MULLER, L. Normas para avaliação de carcaças e concurso de carcaças de novilhos. 2. ed. Santa Maria: Universidade Federal de Santa Maria, 1987. 31 p.

NATIONAL RESEARCH COUNCIL - NRC. Nutrient requirements of dairy cattle. $7^{\text {th }}$ ed. Washington: National Academy Press, 2000. 450 p.
Nutrients requirements of dairy cattle. $7^{\text {th }}$ ed. Washington, D.C.: National Academy Press, 2001. 381 p.

NEIVA, J. N. M.; LEÃO, J. P.; RESTLE, J.; PAULINO, P. V. R.; SANTANA, A. M.; MIOTTO, F. C.; MÍSSIO, R. S. Consumo e desempenho de bovinos de aptidão leiteira em confinamento alimentados com glicerol. Ciência Animal Brasileira, Goiânia, v. 13, n. 4, p. 421-428, 2012.

OLIVEIRA, R. L.; FERREIRA, A. C.; LEÃO, A. G. Suplementação proteica e energética em pastagens. In: SIMPÓSIO DE PRODUÇÃO ANIMAL A PASTO, 1., 2011, Maringá. Anais... Maringá: Estampa, 2011. p. 221245.

PALMQUIST, D. L.; JENKINS, T. C. Fat in lactation rations: review. Journal of Dairy Science, Madison, v. 63, n. 1, p. 1-14, 1980.

PARSONS, G. L.; SHELOR, M. K.; DROUILLARD, J. S. Performance and carcass traits of finishing heifers fed crude glycerin. Journal Animal Science, Champaign, v. 87, n. 2, p. 653-657, 2008.

PELLEGRIN, A. C. R. S.; PIRES, C. C.; CARVALHO, P. S.; PACHECO, P. S.; PELEGRINI, L. F. V.; GRIEBLER, L.; VENTURINI, R. S. Glicerina bruta no suplemento para cordeiros lactentes em pastejo de azevém. Ciência Rural, Santa Maria, v. 42, n. 8, p. 1477-1482, 2012.

PINTO, A. P.; ABRAHÃO, J. J.; MARQUES, J. A. Desempenho e características de carcaça de tourinhos mestiços terminados em confinamento com dietas à base de cana-de-açúcar em substituição à silagem de sorgo. Revista Brasileira de Zootecnia, Viçosa, MG, v. 39, n. 1, p. 198-203, 2010.

PYATT, A.; DOANE, P. H.; CECAVA, M. J. Effect of crude glycerin in finishing cattle diets. Journal of Animal Science, Champaign, v. 85, p. 412, 2007. Supplement 1. (Abstract).

RAMOS, M. H.; KERLEY, M. S. Effect of dietary crude glycerol level on ruminal fermentation in continuous culture and growth performance of beef calves. Journal of Animal Science, Champaign, v. 90, n.3, p. 892-899, 2012.

ROTTA, P. P.; PRADO, R. M.; PRADO, I. N.; VALERO, M. V.; VISENTAINER, J. V.; SILVA, R. R. The effects of genetic groups, nutrition, finishing systems and gender of Brazilian cattle on carcass characteristics and beef composition and appearance: a review. AsianAustralasian Journal of Animal Science, Champaign, v. 22, n. 12, p. 1718-1734, 2009.

RUSSELL, J. B.; WILSON, D. B. Why are ruminal cellulolytic bacteria unable to digest cellulose at low pH? Journal Dairy Science, Madison, v.79, n. 8, p. 15031509, 1996. 
SALIBA, E. O. S.; FERREIRA, W. M.; PEREIRA, R. A. N. Lignin from Eucalyptus grandis as indicator for rabbits in digestibility trials. Tropical e Subtropical Agroecosystems, Mérida, v. 3, n. 1, p. 107-109, 2003.

SILVA, D. J.; QUEIROZ, A. C. Análise de alimentos: métodos químicos e biológicos. 3. ed. Viçosa: UFV, 2002. 235 p.

SMITH, S. B.; CROUSE, J. D. Relative contributions of acetate, lactate and glucose to lipogenesis in bovine intramuscular and subcutaneous adipose tissue. Jornal Nutrition, Toronto, v. 114, n. 4, p. 792-780, 1984.

SNIFFEN, C. J.; OCONNOR, J. D.; VAN SOEST, P. J.; FOX, D. J.; RUSSEL, J. B. A net carbohydrate and protein system for evaluating caule diets. 2. Carbohydrate and protein availability. Journal of Animal Science, Champaign, v. 70, n. 11, p. 3562-3577, 1992.

STROBEL, H. J.; RUSSELL, J. B. Effect of $p H$ and energy spilling on bacterial protein synthesis by carbohydrate limited cultures of mixed rumen bacteria. Journal Dairy Science, Madison, v. 69, n. 11, p. 29412947, 1986.

UNIVERSIDADE FEDERAL DE VIÇOSA - UFV/ SAEG - Sistema de análises estatísticas e genéticas. Versão 8.0. viçosa: Editora UFV, 2000. 142 p.
VALADARES FILHO, S. C.; PAULINO, P. V. R.; MAGALHAES, K. A. Exigências nutricionais de zebuínos e tabelas de composição de alimentos BR CORTE. Vicosa, MG: UFV, DZO, 2006. 142 p.

VALADARES FILHO, S. C.; PINA, D. S. Fermentação ruminal. In: BERCHIELLI, T. T.; PIRES, A. V.; OLIVEIRA, S. G. Nutrição de ruminantes. Jaboticabal: Funep, 2006. p. 51-178.

VAN SOEST, P. J.; ROBERTSON, J. B.; LEWIS, B. A. Symposium: carbohydrate methodology, metabolism, and nutritional implications in dairy cattle. Journal of Dairy Science, Madison, v. 74, n. 10, p. 3583-3597, 1991.

WANG, C.; LIU, Q.; HUO, W. J.; YANG, W. Z.; DONG, K. H.; HUANG, Y. X.; GUO, G. Effects of glycerol on rumen fermentation, urinary excretion of purine derivatives and feed digestibility in steers. Livestock Science, Amsterdam, v. 121, n. 1, p. 15-20, 2009.

WEISS, W. P. Energy prediction equations for ruminant feeds. In: CORNELL NUTRITION CONFERENCE FOR FEED MANUFACTURERS, 61., 1999, Ithaca. Proceedings... Ithaca: Cornell University, 1999. p. 176185. 
